\title{
Comment \\ The dog days of autumn
}

\author{
Gregory A Petsko
}

Address: Rosenstiel Basic Medical Sciences Research Center, Brandeis University, Waltham, MA 02454-9110, USA.

Email: petsko@brandeis.edu

In the world which we know, among the different and primitive geniuses that preside over the evolution of the several species, there exists not one, excepting that of the dog, that ever gave a thought to the presence of man.

Maurice Maeterlinck

Greg Petsko is tied up with teaching, so, by popular demand - actually, he wonders why there never seems to be a demand for more from him - his column will be guest-written this month by his two dogs, the mixed poodle/spaniel Clifford and the chocolate Labrador retriever Mink (Figure 1). They are not strangers to these pages, having written before, to much acclaim. Precisely how they manage to type their text is unclear.

Mink: Did you see the paper in the issue of Science for 2 October 2009 (326:150-153) by Cadieu and coworkers? It's entitled Coat variation in the domestic dog is governed by variants in three genes.

Clifford: What's a domestic dog?

Mink: I'm not sure. I think maybe it's the opposite of a foreign dog.

Clifford: Are you a foreign dog? After all, you're from Labrador.

Mink: No, I'm from New England. My ancestors were from Labrador. And yours were from France and England.

Clifford: Does that mean I'm not a domestic dog? I don't want to be a foreign dog! I don't speak French!

Mink: Calm down. We're both domestic dogs, I'm sure. But we're getting off the subject here. Did you see that paper?

Clifford: No, I didn't. Was it written in French?

Mink: Will you forget about French! It was written in scientific English, which means it's not easy for a little puppy to understand, but I'll explain it to you. It's about the genes that control different coats in dogs.

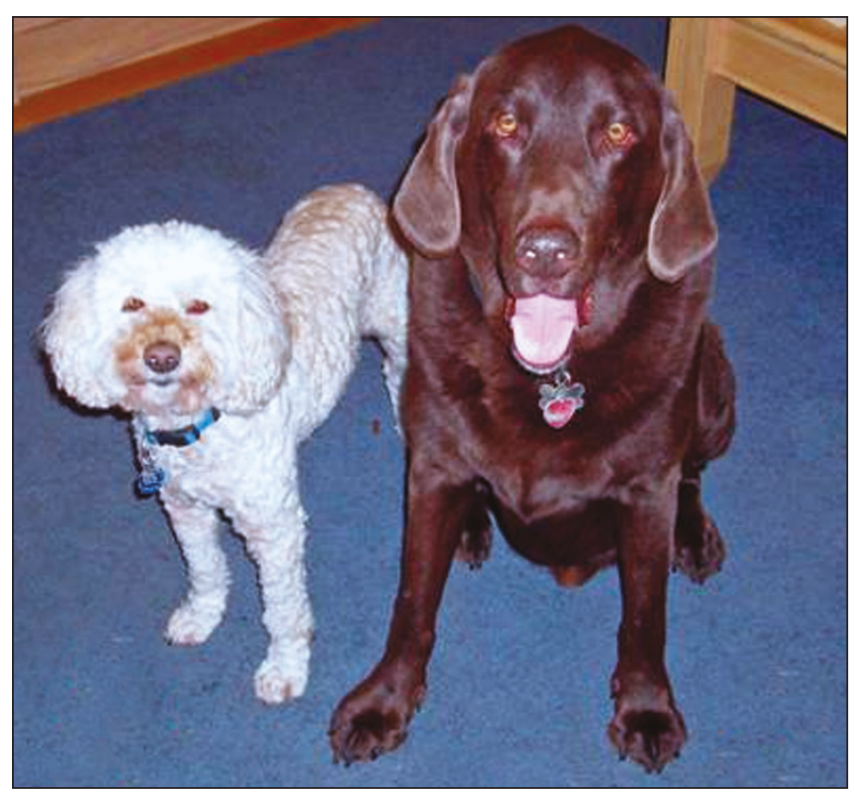

Figure 1

Mink (right) and Clifford proudly display their different coats and wish to remind the Editor that, although they don't work for peanuts, they do work for lamb chops.

Clifford: You mean like how your coat is dark brown and mine is like wheat?

Mink: No, the genes that govern coat color have been known for quite a while. This paper is about the genes that control coat length, growth pattern, and curl. For example, I have a fur coat that's all one color, and it only grows to a certain length and then it stops. I shed in winter -

Clifford: I'll say you do! I've never seen so much brown fur flying around! Why, the carpet in the family room is covered with little mounds of -

Mink: Yes, yes, I know. I can’t help it. But as I was saying, I have solid brown, straight fur while you have patchy offwhite and beige curly hair. Your coat would just keep growing forever and curl into huge mats if you didn't get taken to the groomer for - 
Clifford: I hate the groomer! Hate them!

Mink: Can we stay focused here? I know you hate the groomer. You make that perfectly plain every time Greg tries to take you there. I haven't seen such a performance of suffering since we watched that television broadcast of King Lear with Greg last spring.

Clifford (sotto voce): Hate them!

Mink: OK, we've established that. But the point I'm trying to make is: look how different our coats are.

Clifford: Mine's better. Except for having to go to the groomer. I hate -

Mink (quickly): I'm glad you like your coat. I think mine is perfectly fine, too. And I don't have to go to the groomer. So there.

Clifford (sullenly): What was your point about the paper?

Mink: Oh, yes. The paper. Well, our coats are so completely different, you would think that there would be many genes that were involved in determining those different properties. But the authors of this paper found that's simply not the case. They carried out what are called genome-wide association studies (which is basically just looking for variations in gene sequence that correlate with changes in some property) of more than 1,000 dogs from 80 domestic breeds to identify genes associated with canine fur phenotypes. They were able to take advantage of both inter- and intrabreed variability.

Clifford: What does that mean?

Mink: I think it means that, although dogs' coats vary a lot from breed to breed, like with you and me, they also vary a bit within breeds. Not all poodles have the same kinds of coat, as any groomer can tell you.

Clifford: I hate the groomer!

Mink: Right. Nothing more about groomers, I promise. Anyway, it's an advantage when you have small variations within a breed, because you can use that to find the small number of genes that most likely account for those variations (they stand out against a background that doesn't vary so much since all the dogs are from the same breed), and then you can pay particular attention to those genes when you look for what controls the much larger variations between breeds. That makes genome-wide association studies in dogs much easier and more rewarding than genome-wide association studies in people, where it's harder to find candidate genes, so you have to look at thousands of individuals and it's very expensive.
Clifford (proudly): Dogs are better than people.

Mink: Of course we are. But as I was saying, Greg has talked about this before. He is convinced that, for association studies in people, it would be smart to use the relatively common mutations that give rise to autosomal recessive diseases and examine the carriers for association with other diseases. For example, people with Gaucher Disease are much more likely to get multiple myeloma, so an obvious thing to do would be to see if Gaucher carriers are overrepresented among myeloma patients. Greg thinks that's what the human genome people ought to be doing if they want to make rapid progress on diseases, because the carrier mutations are known to affect the functions of those proteins, so they're much more likely to do something than the common variants that the gene association studies mostly look at. Greg says those people are barking up the wrong tree.

Clifford: Barking up the wrong tree? Why would anybody bark up the wrong tree?

Mink: I have no idea.

Clifford: Can we get back to talking about dogs?

Mink: Sorry. As I was saying, with dogs you can get a good idea what genes to look at as well, from variations within a breed. That's how the people in this paper started their project. The team of scientists, which was headed by Elaine Ostrander of the National Institutes of Health -

Clifford: I've heard of her! She's a genome biologist. We like her. She works on genes responsible for cancer susceptibility in people and dogs. Cancer is the number one killer of dogs. We hate cancer! We hate it almost as much as we hate the gr -

Mink (even more quickly): Yes, she is a great benefactor of the canine race. You may remember that, about two years ago, she headed the team that studied height variation in dogs (Science, 316:112-115, 2007). Dogs have the greatest variation in height of any mammalian species. She discovered that the default for dogs is to be tall, like me, but that a mutation in a single gene, insulin-like growth factor 1, could account for the fact that many dogs are quite small, like Chihuahuas, fox terriers, and, well, like you.

Clifford: I'm not small! I just have short legs for my body height.

Mink: Whatever. The point is, it was a big surprise that one gene could account for such big differences.

Clifford: How did they find that gene? I forget. 
Mink: Exactly the same way they found the genes in this study. They first looked at variation in height within a breed where it varies a lot: Portuguese water dogs. That allowed them to home in on the likely gene. Then they checked it across breeds.

Clifford: President Barack Obama has a Portuguese water dog named Bo, doesn't he? I wonder why he didn't pick a poodle/spaniel mix.

Mink: Or a chocolate Lab. Well, nobody's perfect. Anyway, that discovery sort of made sense because insulin-like growth factor is one of the genes that controls cell growth and lifespan.

Clifford (musing): I'd like to meet Bo. Do you think President Obama would let him play with us?

Mink: Can we stay on the topic here? This column'll be over soon.

Clifford: OK. Did they use Portuguese water dogs in this new study about coat variation too?

Mink: As a matter of fact, they did. One of their same-breed groups comprised 76 Portuguese water dogs, because it's a breed that varies a lot in hair curl. They looked at three phenotypes, actually: hair curl, hair length, and the presence or absence of what they call 'furnishings' - you know, that little moustache and bushy eyebrows you have.

Clifford (proudly): I am well furnished.

Mink: Of course you are. Well, after they looked at a few same-breed groups, they then examined genetic variation across 903 dogs from 80 different breeds. They found that distinct mutations in just three genes, $\mathrm{RSPO}_{2}, \mathrm{FGF}_{5}$, and $K R T 71$, together account for most coat phenotypes in purebred dogs in the United States.

Clifford: You mean my coat is controlled by just three genes?

Mink: Maybe not. They only looked at purebreds, and you're a mixture of two breeds.

Clifford: Are you insulting my mother? I’m just as pure as -

Mink: No, not at all. It's just that, er, uh, more sophisticated dogs like you are too complex for simple genetic analysis.

Clifford: That's me, all right. I'm complicated.

Mink: You can say that again. Anyway, RSPO2 largely controls furnishing, which is interesting, because the gene codes for a protein called R-spondin-2, which is a signaling regulator that synergizes with the Wnt pathway to activate $\beta$-catenin, and Wnt signaling is required for the establishment of hair follicles in mammals. The mutation doesn't seem to change the protein sequence; it probably affects the mRNA level. You know, this same pathway is involved in the development of hair-follicle tumors, or pilomatricomas, which occur most frequently in breeds that have furnishings. Recent studies have shown that a mutation in the EDAR gene, also involved in the Wnt pathway, is responsible for a coarse East-Asian hair type found in humans, and as you know, that hair type has some similarity to canine wirehair.

Clifford: Do you think this pathway controls Greg's hair?

Mink: He's a middle-aged man. What hair?

Clifford: How about the other two phenotypes?

Mink: Curl seems to be determined by the KRT71 gene, which codes for one of the forms of keratin, the major protein component of hair.

Clifford: That makes sense. Does the mutation change the protein sequence?

Mink: Yes, it does. It replaces one amino acid, an arginine, with a tryptophan. But why that leads to curly hair is not obvious. The third gene, FGF5, is involved in hair length.

Clifford: What does that protein do?

Mink: It makes one of the fibroblast growth factors. Makes sense, right?

Clifford: It does. Amazing. And if a dog has all three genes mutated...

Mink: He's a wire-hair.

Clifford: Like our friend Max in the park. Cool. But why is this important - besides the fact that it refers to dogs, of course?

Mink: Isn't that enough? Well, I guess one other reason is that it explains how so many different sizes, shapes and appearances of dog could have arisen in only about 15,000 years of accidental and deliberate breeding. If combinations of only a few genes can have a big effect on morphology and so forth, it won't take that many generations to produce a large number of possibilities. In fact, it's thought that most of the breeds we see today originated since about 1800 , so it really can happen fast. Dog evolution is much faster than evolution of other mammals in the wild. 
Clifford: That's because we're a superior species.

Mink: Obviously. After all, who lies around all day and gets fed, while the other species works to support us?

Clifford: Isn’t evolution wonderful?
Mink: It is, but in our case, I prefer the term intelligent design.

Published: 4 November 2009

doi:10.1186/gb-2009-10-10-112

(C) 2009 BioMed Central Ltd 